\title{
Martensite Formation in the Metallographic Preparation of Austenitic Stainless Steel Welds
}

\author{
J. M. Rodelas, M. C. Maguire, J. R. Michael \\ Sandia National Laboratories, Albuquerque, New Mexico
}

Fusion welding of austenitic stainless steels requires careful control of the proportion of ferrite in the weld metal microstructure. The amount of ferrite in the weld metal directly affects the mechanical response as well as the susceptibility to solidification and environmental cracking [1]. Therefore, accurate metallographic determination of weld metal constitution is of considerable interest. Deformation induced martensite formation in austenitic stainless steels has been observed in base material test samples tested primarily in tension [2-4]. Such deformation-induced martensite, which can be difficult to distinguish from ferrite often present in weld metal microstructures, can lead to misleading measurements of ferrite content and ultimately result in weld behavior which deviates from weld metal constitution predictions based on chemical composition. This study was conducted to examine the effect of metallographic preparation technique on the presence of deformation induced martensite formation in austenitic stainless steel welds.

A Nd:YAG laser was used to produce autogenous welds on vacuum arc remelted 304L stainless steel plate. After welding, plan-view sections of the weld were ground and polished using conventional mechanical grinding and polishing techniques which included grinding with SiC papers, diamond polishing, and final vibratory polishing with colloidal $0.04 \mu \mathrm{m} \mathrm{SiO}_{2}$. Prepared samples were examined using electron backscatter diffraction (EBSD) to determine the balance of ferrite and austenite present in the weld. Figure 1A shows a band contrast EBSD map of the autogenous laser beam weld with red pixels representing scan points indexed as bcc (ferrite). Analysis of the scan region suggests the total area of weld metal indexed as 'ferrite' is approximately $12 \%$. It not uncommon to have some ferrite contained within the weld metal of 304L welds because of its role in preventing solidification cracking. However, if martensite is present as a result of deformation during preparation, the low carbon content associated with the examined alloy $(0.024 \mathrm{wt} \% \mathrm{C})$ will make the low-tetragonality martensite very difficult to distinguish from ferrite.

Welds were also prepared for EBSD by electropolishing, which involves no deformation. Figure $1 \mathrm{~B}$ shows an EBSD band contrast map of an electropolished plan-view section from the same weld as examined previously. The fraction in this electropolished scan region indexed as bcc (ferrite) is approximately $0.2 \%$--substantially lower than welds prepared by mechanical polishing shown in Figure 1A. The additional phase fraction indexed as bcc in the mechanically polished sample is attributed to deformation induced martensite caused by mechanical grinding and polishing, thus resulting in an erroneous ferrite content measurement when mechanically polished.

304L laser welds were also strained at room temperature in tension at slow extension rates (0.0001 in./sec.) until near failure (i.e., necking). Figure 2A shows an electropolished plan view section before tensile testing. As was observed in in Figure 1B, the majority of the scan region is indexed as austenite with the exception of a small amount of residual ferrite represented as red pixels $(<<1 \%$ of scan area) that remains from solidification represented as red pixels. Interestingly, after straining in tension, the weld metal does not show any significant deformation-induced martensite formation as evidenced by the similar proportion of scan points indexed as ferrite after testing. This result indicates plastic deformation in tensile testing for the conditions explored was not able to cause transformation of the austenite to martensite, whereas martensite formed rather readily via mechanical polishing. The

Sandia is a multiprogram laboratory operated by Sandia Corporation, a Lockheed Martin Company, for the US Dept. of Energy's National Nuclear Security Administration under contract DE-AC04-94AL8500 
results presented in this paper suggest that a local shear stress state, such as that encountered in grinding and polishing operations, promotes the formation of deformation induced martensite much more readily than deformation from bulk testing.

\section{References}

[1] J.C. Lippold and D.J. Kotecki, Welding Metallurgy and Weldability of Stainless Steels, Wiley and Sons, (2005), p.165

[2] Odegard, B.C., Metallography, 7, 129-135 (1974)

[3] A. Das, et al. Mat. Sci. Eng. A, 486, 283-286 (2008)

[4] L.E. Murr, K.P. Staudhammer, S.S. Hecker. Met. Trans. A, 13A, 627-635 (1982)

A.)

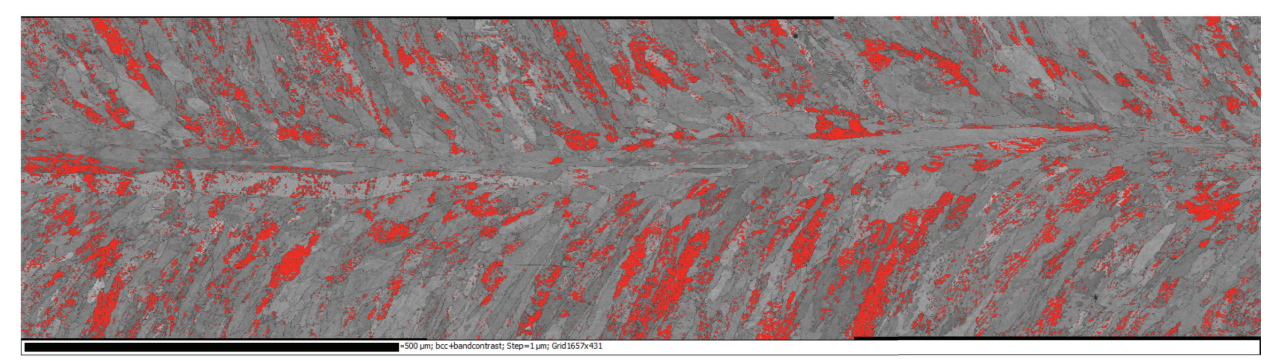

B.)

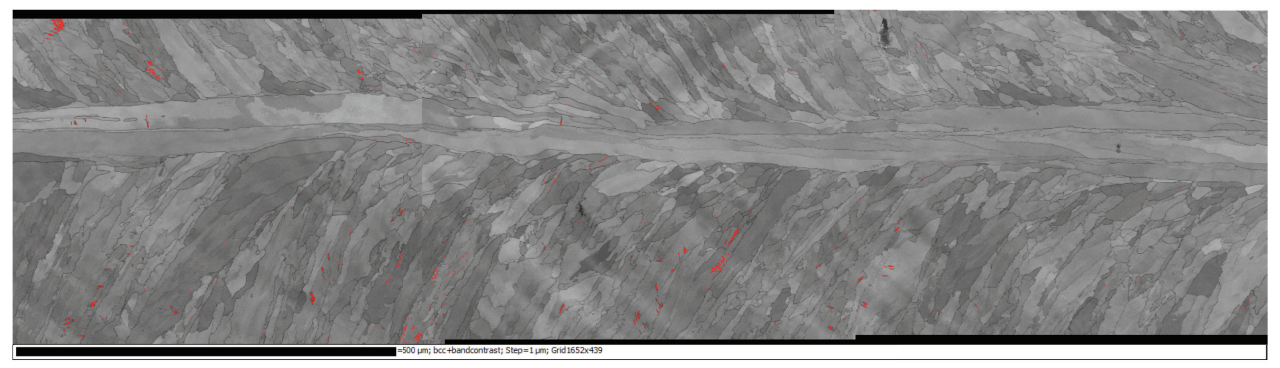

Figure 1. A.) Band contrast map of plan view section of weld metal. Red pixels denote phase indexed 'bcc' ferrite for A.) mechanically polished and B.) electropolished material.

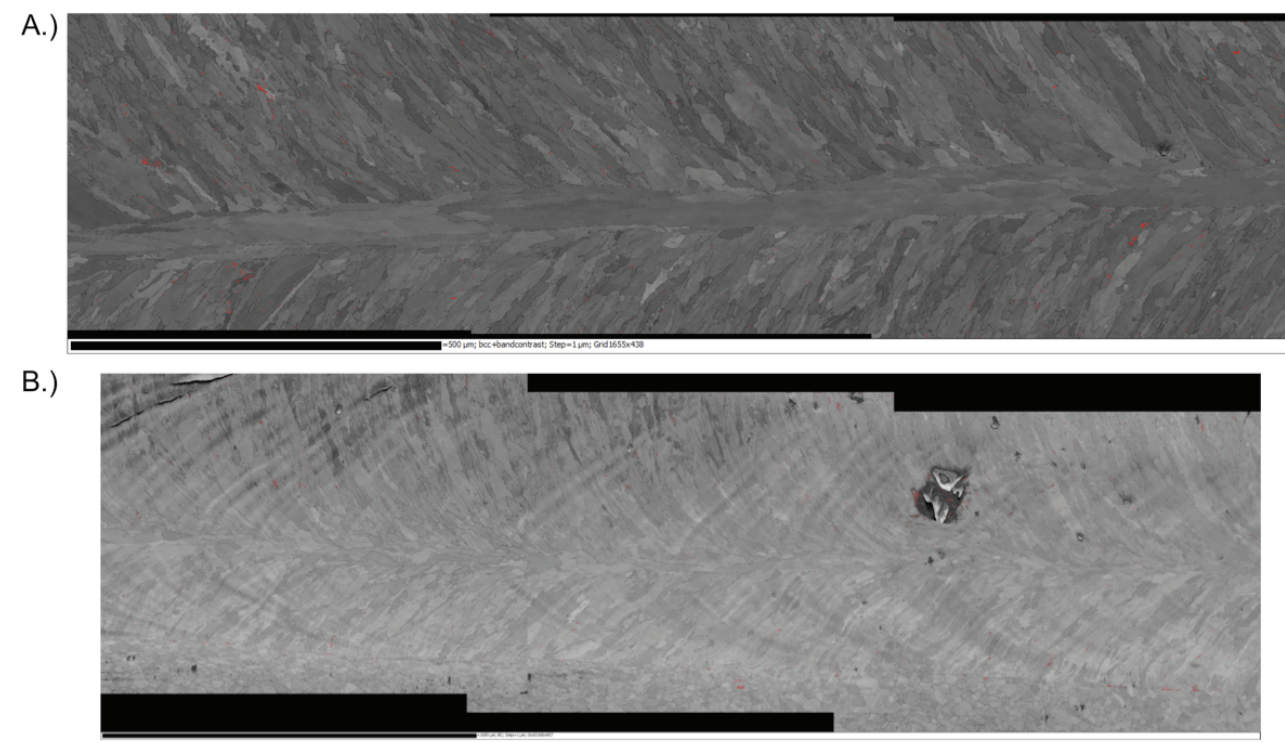

Figure 2. A.) Band contrast map of plan view section of electropolished weld metal tensile test specimen. Red pixels denote phase indexed 'bcc' ferrite for A.) unstrained and B.) strained near failure condition 